\title{
An improved flower pollination algorithm for optimization of intelligent logistics distribution center
}

\author{
$\mathrm{Hu}, \mathbf{W}^{\mathrm{a},{ }^{*}}$ \\ ${ }^{\mathrm{a} S}$ School of Economics and Management, Shanghai University of Electric Power, Shanghai, P.R. China
}

\begin{abstract}
A B S TRACT
It is easy to fall into local optimal solution in solving the optimal location of intelligent logistics distribution center by traditional method and the result of optimization is not ideal. For this, the study puts forward an optimization method of intelligent logistics distribution center based on improved flower pollination algorithm. This method uses the logic self-mapping function to carry out chaotic disturbance to the pollen grains, so that the pollen grain set lacking the mutation mechanism has strong self-adaptability, and the convergence of the optimal solution in the later stage of the algorithm is effectively prevented. The boundary buffer factor is used to buffer the cross-boundary pollen grains adaptively so as to prevent the algorithm from the local optimization, and the convergence speed and the optimization accuracy of the algorithm can be improved obviously in processing the optimal location of intelligent logistics distribution center. The convergence of the algorithm is analyzed theoretically by using the real number coding method, and the biological model and theoretical basis of the algorithm are given. The experimental results show that the proposed method has better performance than the traditional one, and the algorithm outperforms a genetic algorithm and particle swarm algorithm. It provides a feasible solution for the intelligent logistics distribution center location strategy. It affords a good reference for improving and optimizing the internal logistics of the manufacturing system and the operational efficiency of the entire intelligent logistics system.
\end{abstract}

\author{
ARTICLE INFO \\ Keywords: \\ Intelligent logistics; \\ Distribution center; \\ Optimization; \\ Intelligent optimization algorithm; \\ Flower pollination algorithm; \\ Intelligent location
}

*Corresponding author:

hwshiep@shiep.edu.cn

(Hu, W.)

Article history:

Received 18 October 2018

Revised 21 April 2019

Accepted 15 May 2019

\section{References}

[1] Feng, F., Pang, Y., Lodewijks, G., Li, W. (2017). Collaborative framework of an intelligent agent system for efficient logistics transport planning, Computers \& Industrial Engineering, Vol. 112, 551-567, doi: 10.1016/j.cie. 2016.12.044.

[2] Kirch, M., Poenicke, O., Richter, K. (2017). RFID in logistics and production - Applications, research and visions for smart logistics zones, Procedia Engineering, Vol. 178, 526-533, doi: 10.1016/j.proeng.2017.01.101.

[3] Yang, L., Ji, X., Gao, Z., Li, K. (2007). Logistics distribution centers location problem and algorithm under fuzzy environment, Journal of Computational and Applied Mathematics, Vol. 208, No. 2, 303-315, doi: 10.1016/i.cam. 2006.09.015.

[4] Tang, X., Lehuédé, F., Péton, O. (2016). Location of distribution centers in a multi-period collaborative distribution network, Electronic Notes in Discrete Mathematics, Vol. 52, 293-300, doi: 10.1016/i.endm.2016.03.039.

[5] Loree, N., Aros-Vera, F. (2018). Points of distribution location and inventory management model for postdisaster humanitarian logistics, Transportation Research Part E: Logistics and Transportation Review, Vol. 116, 124, doi: $10.1016 /$ i.tre.2018.05.003.

[6] Gutjahr, W.J., Dzubur, N. (2016). Bi-objective bilevel optimization of distribution center locations considering user equilibria, Transportation Research Part E: Logistics and Transportation Review, Vol. 85, 1-22, doi: 10.1016/ j.tre.2015.11.001. 
[7] Holzapfel, A., Kuhn, H., Sternbeck, M.G. (2018). Product allocation to different types of distribution center in retail logistics networks, European Journal of Operational Research, Vol. 264, No. 3, 948-966, doi: 10.1016/ j.ejor.2016.09.013.

[8] Tan, J., Jiang, G., Wang, Z. (2017). Evolutionary game of information sharing on supply chain network based on memory genetic algorithm, Journal Européen des Systèmes Automatisés, Vol. 50, No. 4-6, 507-519, doi: 10.3166/ IESA.50.507-519.

[9] Pham, T.Y., Ma, H.M., Yeo, G.T. (2017). Application of fuzzy delphi TOPSIS to locate logistics centers in Vietnam: The logisticians' perspective, The Asian Journal of Shipping and Logistics, Vol. 33, No. 4 211-219, doi: 10.1016/ j.ajsl.2017.12.004.

[10] He, Y., Wang, X., Lin, Y., Zhou, F., Zhou, L. (2017). Sustainable decision making for joint distribution center location choice, Transportation Research Part D: Transport and Environment, Vol. 55, 202-216, doi: 10.1016/j.trd. 2017.07.001.

[11] Sun, H., Gao, Z., Wu, J. (2008). A bi-level programming model and solution algorithm for the location of logistics distribution centers, Applied Mathematical Modelling, Vol. 32, No. 4, 610-616, doi: 10.1016/i.apm.2007.02.007.

[12] Hua, X., Hu, X., Yuan, W. (2016). Research optimization on logistics distribution center location based on adaptive particle swarm algorithm, Optik, Vol. 127, No. 20, 8443-8450, doi: 10.1016/j.ijleo.2016.06.032.

[13] Malik, S., Kumari, A., Agrawal, S. (2015). Selection of locations of collection centers for reverse logistics using GTMA, Materials Today: Proceedings, Vol. 2, No. 4-5, 2538-2547, doi: 10.1016/i.matpr.2015.07.199.

[14] Coelho, E.K.F., Mateus, G.R. (2017). A capacitated plant location model for reverse logistics activities, Journal of Cleaner Production, Vol. 167, 1165-1176, doi: 10.1016/i.jclepro.2017.07.238.

[15] Zhao, L., Li, H., Li, M., Sun, Y., Hu, Q., Mao, S., Li, J., Xue, J. (2018). Location selection of intra-city distribution hubs in the metro-integrated logistics system, Tunnelling and Underground Space Technology, Vol. 80, 246-256, doi: 10.1016/j.tust.2018.06.024.

[16] Vieira, J.G.V., Toso, M.R., da Silva, J.E.A.R., Ribeiro, P.C.C. (2017). An AHP-based framework for logistics operations in distribution centres, International Journal of Production Economics, Vol. 187, 246-259, doi: 10.1016 Li.ijpe.2017.03.001.

[17] Gao, M., Shen, J., Jiang, J. (2018). Visual tracking using improved flower pollination algorithm, Optik, Vol. 156, 522-529, doi: $10.1016 /$ i.ijleo.2017.11.155.

[18] Salgotra, R., Singh, U. (2017). Application of mutation operators to flower pollination algorithm, Expert Systems with Applications, Vol. 79, 112-129, doi: 10.1016/j.eswa.2017.02.035.

[19] Yang, X.-S., Karamanoglu, M., He, X. (2014). Flower pollination algorithm: A novel approach for multiobjective optimization, Engineering Optimization, Vol. 46, No. 9, 1222-1237, doi: 10.1080/0305215X.2013.832237.

[20] Wang, C.L., Li, S.W. (2018). Hybrid fruit fly optimization algorithm for solving multi-compartment vehicle routing problem in intelligent logistics, Advances in Production Engineering \& Management, Vol. 13, No. 4, 466-478, doi: 10.14743/apem2018.4.304.

[21] Hu, W., Hou, Y., Tian, L., Li, Y. (2015). Selection of logistics distribution center location for SDN enterprises, Journal of Management Analytics, Vol. 2, No. 3, 202-215, doi: 10.1080/23270012.2015.1077481.

[22] $\mathrm{Wu}, \mathrm{Z}$. (2014). Optimization of distribution route selection based on particle swarm algorithm, International Journal of Simulation Modelling, Vol. 13, No. 2, 230-242, doi: 10.2507/IJSIMM13(2)C09.

[23] McFarlane, D., Giannikas, V., Lu, W. (2016). Intelligent logistics: Involving the customer, Computers in Industry, Vol. 81, 105-115, doi: 10.1016/j.compind.2015.10.002. 


\title{
Izboljšan algoritem cvetnega opraševanja za optimizacijo inteligentnega logističnega distribucijskega centra
}

\author{
$\mathrm{Hu}, \mathbf{W}^{\mathrm{a},{ }^{*}}$ \\ ${ }^{a}$ School of Economics and Management, Shanghai University of Electric Power, Shanghai, P.R. China
}

\section{POVZETEK}

Pri določanju optimalne lokacije inteligentnega logističnega distribucijskega centra po tradicionalni metodi je enostavno priti do lokalne optimalne rešitve, vendar tak rezultat optimizacije ni idealen. $V$ ta namen je $v$ študiji predstavljena metoda optimizacije inteligentnega logističnega distribucijskega centra, ki temelji na izboljšanem algoritmu cvetnega opraševanja. Ta metoda uporablja logično funkcijo samopreslikave za vnašanje kaotičnih motenj na zrna cvetnega prahu, tako da ima garnitura zrn brez mehanizma mutacije močno samoprilagodljivost in učinkovito preprečuje konvergenco optimalne rešitve $\mathrm{v}$ kasnejši fazi algoritma. Mejni zaščitni faktor se uporablja za adaptivno prilagajanje čezmejnih zrn, da se algoritmu prepreči lokalna optimizacija, hitrost konvergence in natančnost optimizacije algoritma pa se pri iskanju optimalne lokacije inteligentnega distribucijskega logističnega centra izboljšata. Konvergenca algoritma se teoretično analizira $\mathrm{z}$ uporabo metode kodiranja $\mathrm{v}$ realna števila, podani so biološki model in teoretična osnova algoritma. Eksperimentalni rezultati kažejo, da predlagana metoda doseže boljše rezultate od tradicionalne in da algoritem prekaša genetski algoritem in algoritem roja delcev. Metoda ponuja izvedljivo rešitev za strategijo lociranja inteligentnega distribucijskega centra in podaja dobro referenco za izboljšanje in optimizacijo notranje logistike proizvodnega sistema in operativne učinkovitosti celotnega inteligentnega logističnega sistema.

\section{PODATKI O ČLANKU}

Ključne besede:

Inteligentna logistika;

Distribucijski center;

Optimizacija;

Inteligenten optimizacijski algoritem;

Algoritem cvetnega opraševanja; Inteligentna lokacija

*Kontaktna oseba: hwshiep@shiep.edu.cn (Hu, W.)

Zgodovina članka:

Prejet 18. oktobra 2018

Popravljen 21. aprila 2019

Sprejet 15. maja 2019 